\title{
Cecal Infection, CTCAE
}

National Cancer Institute

\section{Source}

National Cancer Institute. Cecal Infection, CT CAE. NCI Thesaurus. Code C143359.

A disorder characterized by an infectious process involving the cecum. 